\title{
Time for work: Analyzing the role of time perspectives in work attitudes and behaviors
}

\author{
Katarzyna Wojtkowska ${ }^{1} \cdot$ Maciej Stolarski $^{1}$ (D) $\cdot$ Gerald Matthews ${ }^{2}$ \\ Published online: 15 November 2019 \\ (C) The Author(s) 2019
}

\begin{abstract}
Previous research has provided strong evidence for a pronounced role of time perspective (TP) in various areas of human functioning, including cognitive processes, mental and physical health, environmental behaviors, and relationship quality. The aim of the present study was to investigate the role of individual differences in TP in work-related attitudes and behaviors. In a sample of 200 office workers, we administered a set of questionnaires measuring TPs, job satisfaction, work engagement, Organizational Citizenship Behavior (OCB) and Counterproductive Work Behavior (CWB). Additionally, we controlled for the Big Five personality traits which may be related to the work-related outcomes of interest. Analyses of the data revealed that Future-Positive TP predicted more desired work-related outcomes, i.e., higher job satisfaction, work engagement, and OCB, and lower CWB. An opposite pattern of associations was observed for Present-Fatalistic, Deviation from Balanced Time Perspective, and (partially) for Future-Negative TPs. The vast majority of these effects were still significant after controlling for personality traits. Using path modelling we also demonstrated that the effects of TPs on work behaviors (OCB and CWB) are mostly mediated by job satisfaction and engagement. The present results suggest that TP theory may prove to be a useful tool in organizational psychology for understanding individual differences in work behaviors.
\end{abstract}

Keywords Time perspective $\cdot$ Balanced time perspective $\cdot$ Job satisfaction $\cdot$ Work engagement $\cdot$ Organizational citizenship behavior $\cdot$ Counterproductive work behavior

\section{Introduction}

The behaviors of individual employees remain a crucial determinant of success of organizations (e.g., Robbins and Judge 1993). Two types of actions that have attracted the attention of both organizational researchers and practitioners are Organizational Citizenship Behaviors (OCB; Smith et al. 1983) and Counterproductive Work Behaviors (CWB; Robinson and Bennett 1995). Examples of OCBs are when the worker voluntarily helps or assists others in the workplace, or promotes the excellence of their employer without either an explicit or implicit promise of reward for their behavior (Organ 1988). CWBs are intended to have a detrimental effect on

Maciej Stolarski

mstolarski@psych.uw.edu.pl

1 Faculty of Psychology, University of Warsaw, Stawki Str. 5/7, 00-183 Warsaw, Poland

2 Institute for Simulation and Training, University of Central Florida, Orlando, FL, USA organizations and their members. They include overt acts such as aggression and theft and more passive acts, such as purposely failing to follow instructions or doing work incorrectly (Fox et al. 2001). Consequences of both OCBs and CWBs may be profound (e.g., Murphy 1993; Podsakoff et al. 2009): thus, identifying their determinants is of high importance.

In this article, we explore the role of Time Perspective (TP) (Zimbardo and Boyd 1999; Stolarski et al. 2015, 2018) as a basis for understanding the individual-level characteristics that underpin organizational behaviors. TP broadly refers to the extent to which people frame their experiences in terms of past, present and future. Zimbardo and Boyd (2008) describe TP as one of the most powerful influences on human behavior, which may also be relevant within the organizational context. Existing organizational research has focused especially on future TP as a factor promoting work motivation and goal-setting (Seijts 1998). Future-oriented people plan ahead and are willing to delay gratification to accomplish long-term goals (Zimbardo and Boyd 1999), an orientation likely to promote more prosocial and fewer antisocial behaviors at work.

However, there are several challenges to establishing that TP is a relevant individual-difference factor for organizations. First, 
there are multiple aspects of TP that may be differentially related to organizational outcomes. Second, dimensions of TP overlap with broad personality traits such as those of the Five Factor Model (FFM: Costa and McCrae 2009). The influence of TP on organizational behavior should be distinguished from temperamental factors such as positive and negative affectivity. Third, some perspectives on TP emphasize its cognitive elements such as forward planning (Seijts 1998), but TP also has important emotional and motivational aspects (e.g., Matthews and Stolarski 2015; Stolarski and Matthews 2016). In the organizational setting, behavioral impacts of TP may reflect its effects on affectively-infused constructs such as job satisfaction and work engagement.

The current study aimed to explore the role of multiple TP dimensions in explaining variability in CBOs and CWBs, to test the incremental validity of TP with respect to the FFM, and to investigate work engagement and work satisfaction as potential mediators of TP effects. In the remainder of this section, we introduce the organizational constructs of interest, review existing findings on personality correlates, and justify a role for TP beyond general personality. Specifically, we hypothesize that individual differences in temporal orientations may also reveal their regulative character within the organizational context, influencing work behaviors via their effects on work engagement and job satisfaction.

\section{Organizational Citizenship Behavior (OCB)}

OCB is defined as "performance that supports the social and psychological environment in which task performance takes place" (Organ 1997, p. 95). It includes behaviors that are discretionary and are not linked to formal rewards or punishments. Reviews and meta-analyses (Organ and Ryan 1995; Podsakoff et al. 2000; LePine et al. 2002; Hoffman et al. 2007) highlight the main antecedents of OCBs. They can be categorized into four types: 1) individual characteristics (employee attitudes, dispositional variables, employee role perceptions, individual differences), 2) task characteristics (task feedback, task routinization, intrinsic satisfaction of the task), 3) organizational characteristics (group cohesion, perceived organizational support), and 4) leadership behaviors (transformational leadership, articulating a vision, providing an appropriate model, fostering the acceptance of group goals, intellectual stimulation, contingent reward behavior, supportive leader behaviors, leader-member exchange). Podsakoff et al. (2009) confirmed that OCBs are associated with positive outcomes at both the individual level (e.g., employee performance, low absenteeism) and the organization level (e.g., productivity, efficiency, customer satisfaction).

\section{Counterproductive Work Behavior (CWB)}

CWB refers to voluntary harmful acts that are damaging to an organization. The construct covers numerous types of act including theft, substance use, sabotage, interpersonal violence, and absenteeism (Spector et al. 2006). CWBs are highly damaging to organizations in terms of financial costs, lower productivity, and damage to employee morale (Mount et al. 2006). A recent meta-analysis identified a general factor underlying different types of CWB, although multiple facets were also differentiated (Marcus et al. 2016). Distinctions can also be made based on the severity of the behavior, and whether acts target the organization or individual coworkers (Robinson and Bennett 1995). CWB is also associated with a range of negative attitudes and emotions (e.g., Judge et al. 2006; Spector and Fox 2002). CWB is defined in relation to harmful outcomes rather than specific antecedents (Marcus et al. 2016), but influences on CWB may include stress, perceived injustice, incivility, and organizational restrictions (e.g., Spector and Fox 2005). Personality factors associated with interpersonal deviance and poor impulse control are also associated with CWBs (Berry et al. 2007; Judge et al. 2006). A meta-analysis (Dalal 2005) suggested only a modest negative association between OCB and CWB $(r=-.27)$, justifying their treatment here as distinct outcome variables.

\section{Work Engagement}

Work engagement is an affective-motivational state of workrelated well-being, emotional connection, and fulfillment (Bakker et al. 2008). Its facets include vigor, dedication, and absorption in work (Schaufeli and Bakker 2004). Work engagement is related to both job resources, such as job control, supervisory support, and reward recognition, and to personal qualities including self-esteem, self-efficacy, internal locus of control, and effective emotion-regulation (Bakker 2011; Halbesleben 2010). A meta-analysis (Christian et al. 2011) found an uncorrected mean-weighted correlation of 0.29 between work engagement and task performance. This study also found that, although work engagement was substantially positively correlated with job satisfaction, both variables predicted performance independently. Additional positive consequences include customer satisfaction and financial returns (Xanthopoulou et al. 2009). Work engagement relates positively to OCB (Babcock-Roberson and Strickland 2010) and negatively to CWB (Den Hartog and Belschak 2012), suggesting that engagement might mediate personality effects on work behaviors.

\section{Job Satisfaction}

Job satisfaction refers to both positive attitudes to the job and to pleasant work-related emotions, although scales for the construct differ in the extent to which they emphasize its cognitive-evaluative or affective aspects (Judge et al. 2012). Various situational and personality factors feed into job satisfaction (Judge et al. 2001; Locke 1976). Organizational factors are too numerous to list in full. They include evaluations of 
tasks performed at work such as their significance and variety (Hackman and Oldham 1976), fairness of pay and recognition (Spector 1997), and lower incidence of workplace stressors, including social stressors such as role ambiguity (Fila et al. 2014). Job satisfaction is reliably though modestly related to work performance, although it is not necessarily a direct causal influence on performance (Judge et al. 2001; Taris and Schaufeli 2015).

Job satisfaction is also associated with both OCB and CWB. The emotional elements of job satisfaction may play a critical role in these relationships. Spector and Fox (2002) propose that emotions mediate the effect of the environment on the behavior of employees: positive emotions enhance engaging in OCB and negative emotions amplify engaging in CWB. OCBs are motivated by a desire to reciprocate jobrelated positive emotions, not by the expectation of reward (Organ and Kanovsky 1989). Additionally, people in positive mood are more likely to manifest prosocial behavior (Clark and Isen 1982). A meta-analysis (LePine et al. 2002) reported a correlation of 0.20 between job satisfaction and OCB. Job satisfaction is also a predictor of lower levels of CWB: Dalal (2005) reported a mean $r$ of -.29. Czarnota-Bojarska (2015) described 'avenger' employees, characterized by a high level of CWB and low job satisfaction. Personality traits associated with regulation of emotions may thus influence such outcomes.

\section{Time Perspectives}

TP can be considered both as process, when conceptualized as an ongoing cognitive framing of present experiences, and as a trait, when understood as a stable, habitual focus on particular time frame(s), i.e., the past, the present, or the future (Zimbardo and Boyd 1999). From a trait perspective, Zimbardo and Boyd (1999) distinguished five TPs, measured with the Zimbardo Time Perspective Inventory (ZTPI): PastPositive, Past-Negative, Present-Fatalistic, PresentHedonistic, and Future. Carelli et al. (2011) broadened the TP universe by developing a Future Negative dimension, and slightly modifying traditional Future TP, labeling it Future Positive. They showed that the six-factor model optimized fit in a confirmatory factor analysis of their extended ZTPI. Recently, similar results were obtained in a Polish sample (Jochemczyk et al. 2017). We can briefly define the organizational relevance of each TP in the extended model as follows:

- Past-Positive: A warm, sentimental view of the past that may encourage fond memories and evaluations of past work experiences

- Past-Negative: An aversive view of the past that may bias retrieval of negative memories of work and negative work evaluations
- Present-Hedonistic: Pleasure-focused, impulsive attitudes to life that may conflict with a responsible, serious orientation to work

- Present-Fatalistic: Beliefs that life is primarily shaped by chance rather than personal striving, which may encourage detachment and even apathy at work

- Future-Positive: An orientation towards securing rewards through advance planning that may enhance work motivation and awareness of positive occupational outcomes such as promotion, recognition, and fulfillment through work

- Future-Negative: An orientation towards future threats that may heighten awareness of negative outcomes, such as termination, poor performance at work, and difficulties with coworker relationships

In an ideal situation, an individual is able "to switch effectively among TPs depending on task features, situational considerations, and personal resources, rather than be biased towards a specific TP that is not adaptive across situations" (Zimbardo and Boyd 1999, p. 1285). This flexibility of temporal frames can be operationalized as balanced time perspective (BTP). Measures of BTP have proven to be robust positive predictors of subjective well-being (e.g., Boniwell et al. 2010; Zhang et al. 2013). Within the organizational context, unbalanced TP was related to increased acceptance of unethical business behavior (Unger et al. 2019).

Existing organizational research on TP has focused on Carstensen's (2006) concept of future time perspective (FTP) as the individual's perceived remaining time of life. Occupational FTP refers to perceived remaining time in employment, and is associated with higher work engagement, job satisfaction, organizational commitment and other positive outcomes (Henry et al. 2017; see also a recent meta-analysis by Rudolph et al. 2018). However, Carstensen's conceptualization of FTP as a time horizon should be distinguished from Zimbardo and Boyd's (1999) construct, which refers to broad cognitive schemas for thinking about the future without any specific end-point (Rutt and Löckenhoff 2016). Empirically, the Carstensen (2006) and ZTPI measures are independent, and only the former version of FTP is substantially (negatively) correlated with age (Laureiro-Martinez et al. 2017; Rutt and Löckenhoff 2016). Thus, existing work supports the relevance of temporal experience to work behaviors (Henry et al. 2017), but very few studies have addressed the organizational relevance of the Zimbardo and Boyd (1999) TP constructs. For example, future TP is associated with better career decision-making, but low levels of past-negative, presenthedonic and present-fatalistic TPs additionally contribute to prediction of career decision-making outcomes (Taber 2013). More recently, Bajec (2018) provided initial evidence for marked effects of TPs, operationalized in-line with Zimbardo's conceptualization, on job satisfaction. He showed 
that both particular TP dimensions and BTP predict various aspects of job satisfaction, with age, gender and personality traits are controlled. Finally, Wei (2012) used an earlier, narrow version of the Zimbardo's measure, containing only two subscales - future and present - to test their moderating effects on the association between Person-Organization (P-O) fit and OCB. The study showed that the effect of P-O fit on OCB was much weaker among employees with elevated present orientation. No direct effects of TPs on OCB were obtained. However, the preliminary version of the TP inventory applied in that study is characterized by poor reliability and it does not capture the qualitative differences between different forms of particular orientation (e.g., it does not differentiate between fatalistic and hedonistic forms of present orientation, moreover it does not include past TPs). In all, results of the studies briefly reviewed above seem to provide initial evidence for the role of TPs in organizational attitudes and behaviors, and thus they support some of the major hypotheses of the present research.

The various particular TPs may underpin crucial regulatory processes, in terms of emotions (Matthews and Stolarski 2015; Stolarski and Matthews 2016), motivations (Lens et al. 2012) and resulting behaviors (see Stolarski et al. 2015, for a review), including cognitive performance (Zajenkowski et al. 2016). On this basis, we anticipate that TPs should be related proximally to work emotions, attitudes and emotions, and hence to behaviors including OCBs and CWBs. In general, future and past-positive TPs are associated with higher life satisfaction, whereas future-negative, past-negative, and present-fatalistic TPs tend to be maladaptive (Stolarski and Matthews 2016). We expect similar associations in relation to organizational outcomes, but TPs may have some more specific influences on behaviors in the work context.

Future TP captures expectations of rewards gained through planning and sustaining effort and motivation, and so should be associated with work engagement. It is also associated with energetic arousal, which reflects positive, approach-oriented mood (Stolarski et al. 2014), implying a positive association with job satisfaction. Conversely, Future-Negative TP reflects a future focus loaded with negative emotionality, especially anxiety (Carelli et al. 2011), which should produce lower job satisfaction. Its expected associations with work engagement are more equivocal, as anxiety may be motivating, but negative expectations and perceived insecurity about one's future in the organization are likely to lower engagement.

Present-Fatalistic TP is associated with perceived lack of influence over one's own situation, resulting in frustration and aggressive behaviors (Stolarski et al. 2016b), which may be expressed especially in higher CWBs. To the extent that Present-Fatalistic is associated with external locus of control, we expect lower work engagement and satisfaction. The implications of Present-Hedonistic TP are more equivocal. Maladaptive features of this TP include higher procrastination (Díaz-Morales et al. 2008; Ferrari and Díaz-Morales 2007) and aggression (Stolarski et al. 2016a, b), but it is also associated with more positive interpersonal relations (Sircova and Mitina 2008). The ambivalent character of Present-Hedonistic TP in the organizational context thus makes predictions difficult.

The past orientations tend to be more 'experiential' than 'strategic' (see Stolarski et al. 2014), so that they influence affective experiences more strongly than actual behaviors (Matthews and Stolarski 2015). Thus, we expected appropriate associations between job satisfaction and Past-Positive and Past-Negative TPs, with possible indirect effects on behaviors.

Finally, the notion of balanced TP as the adaptive composition of multiple temporal perspectives is a fundamental characteristic that influences affective and behavioral regulation, resulting in elevated levels of psychological well-being (Zimbardo and Boyd 1999; Boniwell et al. 2010; Zhang et al. 2013) and diminished psychopathology (Stolarski and Cyniak-Cieciura 2016; Styła et al. 2019). Thus, the magnitude of deviation from BTP should be associated with lower work engagement, decreased job satisfaction, lower OCB, and elevated CWB. To sum up, on the most general level, TP may be viewed as a set of factors exerting vital effects on personal and social adaptation (Stolarski et al. 2018). Within the organizational context, its effects should be observable both at the level of attitudes, and actual behaviors.

\section{Personality Correlates of OCB and CWB}

Existing work on individual differences in workplace behavior has focused on a range of personality factors including the 'Big Five' traits of the FFM (for reviews see Burch and Anderson 2009; Hough et al. 2015): Neuroticism (N), Extraversion (E), Conscientiousness (C), Agreeableness (A), and Openness $(\mathrm{O})$. Table 1 summarizes FFM correlates of the organizational constructs relevant here established in relevant literature reviews. Note that Berry et al.'s (2007) metaanalysis divides CWB into behaviors directed against the organization and against the individual. All five traits appear to play some role in adjustment to work. Low N, High C and high A generally relate to positive outcomes whereas $\mathrm{E}$ and $\mathrm{O}$ are more selectively linked to high work engagement.

The FFM also overlaps with dimensions of TP conceptually and empirically. The more robust associations $(r \geq .3)$ between TP and the FFM reported in multiple studies (Kairys and Liniauskaite 2015) include those between Future and C, Present-Hedonistic and E, and Past-Negative and N. Table 1 shows that correlations between the FFM and organizational criteria are generally modest in magnitude, especially for OCB, implying that additional constructs have potential for improving predictive validity. From a conceptual standpoint, individual differences in the various dimensions of TP are linked to different elements of the narrative self-schema (Matthews and Stolarski 2015). Multiple personality traits 
Table 1 Associations between the Big Five personality traits and organizational behaviors

\begin{tabular}{lllllll}
\hline Construct & Data Source & $\mathrm{N}$ & $\mathrm{E}$ & $\mathrm{C}$ & $\mathrm{A}$ & $\mathrm{O}$ \\
\hline OCB & Chiaburu et al. (2011) & -.10 & .07 & .14 & .11 & .11 \\
CWB (Org.) & Berry et al. (2007) & .20 & -.07 & -.34 & -.25 & -.03 \\
CWB (Individual) & Berry et al., (2007) & .20 & -.02 & -.19 & -.36 & -.07 \\
Work Engagement & Schaufeli (2016) & -.27 & .29 & .32 & .17 & .27 \\
Job Satisfaction & Bruk-Lee et al. (2009) & -.25 & .12 & .16 & .13 & -.02 \\
\hline
\end{tabular}

All sources are meta-analyses, except for Schaufeli (2016) which provides a sample-weighted correlation

$N$ Neuroticism, $E$ Extraversion, $C$ Conscientiousness, $A$ Agreeableness, $O$ Openness, Org. Organizational shape the various cognitive and affective aspects of the selfschema throughout development. For example, conscientiousness focuses the child's attention onto the future and elements of Future TP including delay of gratification and needs to plan for future events, building a schema for the future time frame that is related to personality but also distinct from any single trait (Matthews and Stolarski 2015). Other traits contribute to other aspects of TP. Both personality and TP are multifactorial and so relationships between these constructs are complex; further review of the distinctive features of each of Zimbardo and Boyd's (1999, 2008) dimensions has been provided by Kairys and Liniauskaite (2015) and Cunningham et al. (2015). A subsidiary objective of this study was to test compare the FFM and TP as predictors of the organizational variables. Previous studies have found that TP dimensions predict well-being criteria with the FFM controlled, including life satisfaction (Zhang and Howell 2011) and mood (Stolarski and Matthews 2016).

\section{The Present Study: Rationale and Hypotheses}

In the present study we aimed to investigate the association between TP and four dimensions describing individuals' functioning in the organizational context. Zimbardo and Boyd (1999, 2008) emphasize the multidimensional nature of TP, and so we expected that each TP dimension would be associated with a distinct set of organizational outcomes.

Hypotheses were as follows:

H1. Based on the theoretical framework of TP theory (see Zimbardo and Boyd 1999; Stolarski et al. 2015), we hypothesized that Future and Past-Positive TPs would be associated with more positive outcomes, i.e., higher work engagement, job satisfaction, and OCB, and lower CWB. Conversely, Future-Negative, Past-Negative and PresentFatalistic TPs would be associated with more negative outcomes.

H2. Deviations from BTP should be associated with more negative organizational outcomes.

H3. Based on the model proposed by Spector and Fox (2002), associations between TPs and behavioral outcomes (OCB and CWB) should be mediated via job satisfaction and work engagement. This hypothesis was tested by testing the fit of appropriate path models to the data. An additional model was fitted including BTP as the independent variable in the model.

H4. We anticipated that the FFM dimensions would be differentially related to organizational outcomes, as summarized in Table 1. However, the majority of associations between the ZTPI and organizational outcomes should remain significant with the FFM statistically controlled. We included a brief measure of the FFM to test this hypothesis.

\section{Method}

\section{Participants}

The sample comprised 200 office workers (61.7\% women), who were Poles of Caucasian ethnicity, aged between 20 and $65(M=32.05$ years, $S D=11.42)$. They were employed in the positions of specialists, junior managers, and mid-level managers. All subjects were recruited using a snowball method from a number of companies, representing financial or pharmaceutical sectors. They consented to participate in a "study of the role of attitudes towards time in behavior at work", without monetary compensation. The packet of measures was completed in isolation. In order to provide anonymity subjects were asked to put the questionnaires in an envelope and return them to the administrator of the study.

\section{Measures}

Time Perspectives were measured using the Zimbardo Time Perspective Inventory (ZTPI; Zimbardo and Boyd 1999) in a revised form provided by Carelli, Wiberg and Wiberg (SZTPI; 2011), including Future Positive and Future Negative scales. Detailed information regarding psychometric properties of the Polish language version of the S-ZTPI, including the evidence for supremacy of the six-factor solution over the 
original five-factor model, has been provided by Jochemczyk et al. (2017). Internal consistency of the scales was measured with Cronbach's alpha coefficient, ranging from .73 (PastPositive) to .83 (Past-Negative). The Deviation from the Balanced Time Perspective index (DBTP: Stolarski et al. 2011), based on the ZTPI scores, was used as an indicator of BTP. A DBTP value of zero indicates optimal time perspective whereas positive values indicate that an individual's time perspective is "out of balance" and maladaptive (see Stolarski et al. 2015, for a review of calculation methods).

Job Satisfaction was measured using CzarnotaBojarska's scale, validated previously as predictor of CWB in a Polish office worker sample (CzarnotaBojarska 2015). It assesses seven components of satisfaction: amount of earnings, possibility of advancement, selfreliance at work, opportunity to learn, relations with superiors, relationships with colleagues, perceived stability of employment, and working conditions (cf. Locke 1976). Each of eight items are rated on a seven-point scale, ranging from 1 ("I am very dissatisfied") to 7 ("I'm very satisfied"). The mean item rating is calculated. Cronbach's alpha coefficient was .76.

Work Engagement was measured with the Utrecht Work Engagement Scale (UWES; Schaufeli et al. 2002) in the Polish adaptation by Szabowska-Walaszczyk et al. (2011). The questionnaire consists of 17 items related to three aspects of engagement: vigor, dedication and absorption. The answers are rated on a seven-point scale, ranging from 0 ("never") to 6 ("every day"). Overall score was calculate. In the present study Cronbach's alpha was .92 .

Counterproductive work behaviors were measured using the Counterproductive Behavior (CPB) Questionnaire (Czarnota-Bojarska 2015). The scale was is based on Robinson and Bennett's (1995) typology of deviant workplace behaviors. Items refer to specific behaviors, not attitudes or beliefs. They include minor organizational offenses (e.g., personal use of company property), major organizational offenses (e.g., dishonest expense reporting), minor interpersonal offenses (e.g., gossiping about coworkers), and major interpersonal offenses (e.g., harassing a coworker). The tool consists of 33 test items, rated on a five-point Likert-type scale. Mean item rating is calculated. In the present study Cronbach's alpha amounted to .90 .

Organizational citizenship behaviors were measured with the OCB Questionnaire (Czarnota-Bojarska 2011). The scale consists of 33 statements, describing behaviors that are beneficial for the organization (Organ 1988). Items reflect seven classes of behaviors: 1) Helping Behavior, 2) Sportsmanship, 3) Organizational Loyalty, 4) Organizational Compliance, 5) Individual Initiative, 6) Civic Virtue, and 7) Self Development. The items are rated on a five-point Likerttype scale. Overall score was calculated as the mean item rating. In the present study Cronbach's alpha was .90 .
The Big Five personality traits were measured using the Ten Item Personality Inventory (TIPI; Gosling et al. 2003) in the Polish adaptation by Łaguna et al. (2014). This brief measure was used because of time constraints. The questionnaire measures the Big Five traits via 10 items rated on a sevenpoint Likert scale. It was designed for use in studies in which very short measures are required for practical reasons, and the Big Five is not the primary topic of interest. Gosling et al. (2003) argue that Cronbach's alpha may be misleading for very short scales, especially those designed for content validity rather than homogeneity. In their data both test-retest reliability and convergence with longer Big Five scales exceeded .70; similar results were obtained in the Polish population (Laguna et al. 2014).

\section{Results}

\section{Correlates of Occupational Variables}

Table 2 shows means, standard deviations and intercorrelations of study variables. The table includes age and gender, but these factors were unrelated to the work-related variables and so they were not analyzed further.

The organizational variables were intercorrelated as expected. Job satisfaction and work engagement were associated with both OCBs (positively) and CWB (negatively). The correlations suggest a role for TPs in the context of work. H1 was partially supported, in that Future-Positive was associated with a more adaptive pattern of organizational variables, i.e., higher CWB, lower OCB, and higher work engagement. Present-Fatalistic was associated with the opposite pattern of associations consistent with it being a maladaptive TP for work. Two other TPs expected to be maladaptive correlated significantly with only some of the organizational criteria, in the expected directions. Future-Negative proved significantly negatively associated with work engagement and positively with CWB; Past-Negative correlated significantly only with lower work engagement. There were no significant correlations between work variables and the two remaining TPs, Past-Positive and Present-Hedonistic. Supporting H2, the DBTP coefficient proved to be significantly associated with higher work engagement, job satisfaction, OCB, and with lower CWB.

\section{Multivariate Modeling}

To test whether data were compatible with mediating roles for job satisfaction and work engagement, two path models were fitted using maximum likelihood estimation in SPSS Amos for Windows. Models included those three TP dimensions that were significantly associated with the behavioral criteria in the correlational analyses. TPs were permitted to intercorrelate, as 


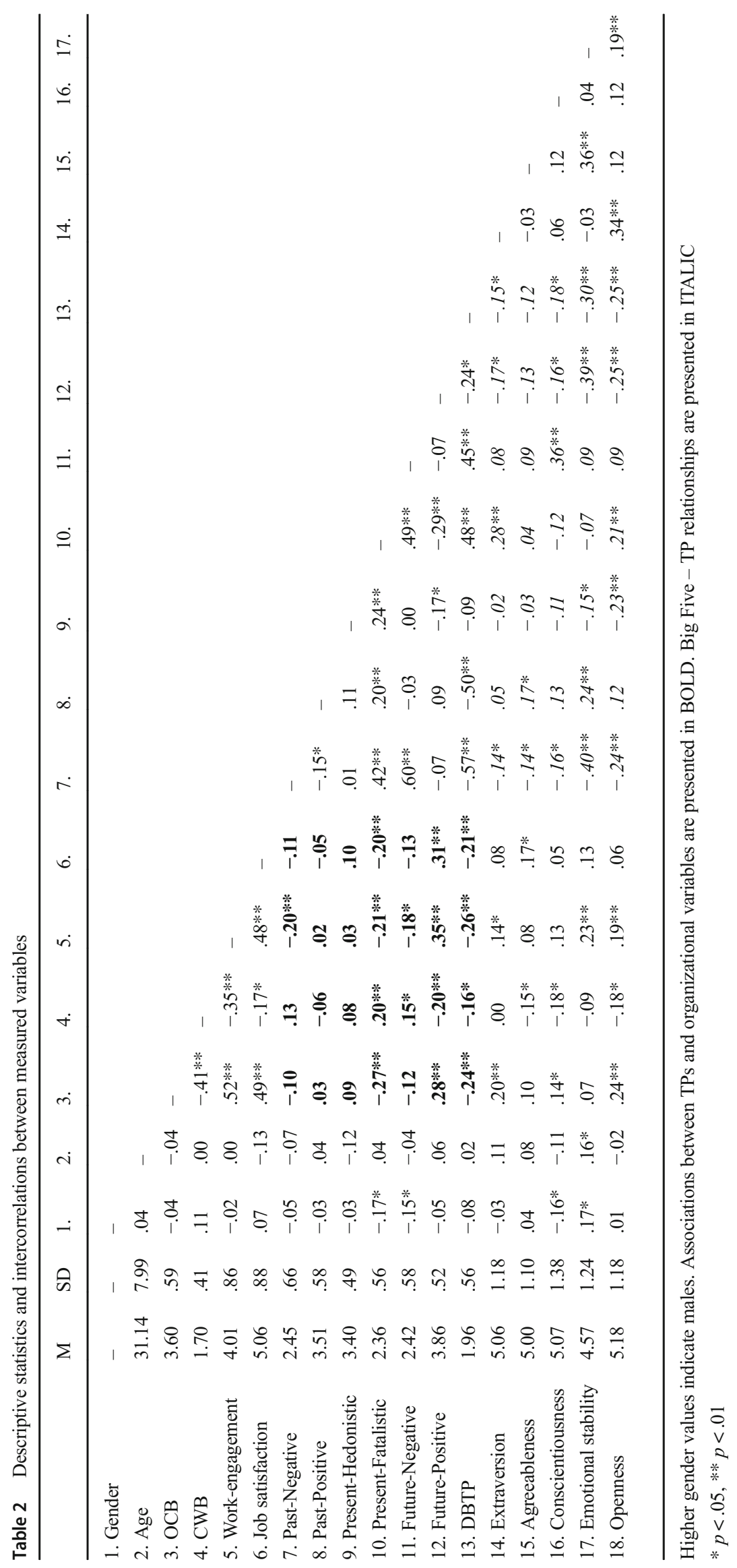


were error terms for the mediating variables, given that these constructs are conceptually and empirically related (Harter et al. 2002). The first model tested was a full mediation model. Based on the correlations, all three TPs influenced work engagement, and Present-Fatalistic and Future-Positive affected job satisfaction. Paths were included from both mediating variables to both behavioral outcomes. Fit for the full mediation model was rather poor $\left(\chi^{2}=45.179, d f=7, p<.001, \chi^{2} / d f=\right.$ $6.454, \mathrm{AGFI}=.768, \mathrm{CFI}=.845$, RMSEA $=.166$ ). Based on modification indices, the job satisfaction - CWB path was removed, and a path added directly linking Present-Fatalistic with OCB. Fit statistics were improved leading to excellent model fit $\left(\chi^{2}=7.158, d f=7, p=.413, \chi^{2} / d f=1.023\right.$, AGFI $=.960$, CFI $=.999$, RMSEA $=.011$ ).

The model (see Fig. 1) suggests that the majority of effects of TPs on OCB and CWB take place indirectly via job satisfaction and work engagement. The strongest TP paths are those for Future-Positive. Effects on CWB depend only on work engagement, whereas there are multiple influences on OCB. The additional direct path from Present-Fatalistic to OCB suggests that some other intermediary mechanism may operate for this TP.

Next, we developed a corresponding model, with the BTP index included as the independent variable in place of the individual TPs (see Fig. 2). In this case, a full mediation model revealed excellent fit $\left(\chi^{2}=2.490, d f=3, p=.477, \chi^{2} / d f\right.$ $=.830, \mathrm{AGFI}=.975, \mathrm{CFI}=1.000, \mathrm{RMSEA}=.000$ ), so no modifications were necessary. The effects of DBTP on work behaviors were entirely explained by work engagement and job satisfaction. In general, multivariate modeling supported $\mathrm{H} 3$, except for the need to include a small direct effect of Present-Fatalistic.

\section{Correlates of the Big Five}

The Big Five traits displayed associations with the work-related variables that were partly consistent with prior expectations (see Table 2). For example, Conscientiousness was significantly associated with higher OCB and lower CWB, but not with the mediating constructs (satisfaction and engagement). Agreeableness was related to lower CWB and higher satisfaction. The association between Emotional Stability (low Neuroticism) and higher engagement matches previous findings but this dimension was not significantly correlated with the behavioral variables. Extraversion and Openness were more strongly positively related to OCB than previous studies would suggest; Openness was further negatively associated with CWB. However, significant positive associations between these two traits and work engagement are consistent with previous findings.

Also, TP dimensions were associated with personality traits, consistent with existing results (see Kairys and Liniauskaite 2015; Stolarski and Matthews 2016), e.g., associations of Future-Positive with Conscientiousness, FutureNegative and Past-Negative with Emotional Stability, and Present-Hedonistic with Extraversion. We therefore tested whether the TP - work variable correlations remain significant after controlling for the Big Five personality traits, using partial correlation analysis for all coefficients that proved significant in bivariate correlation analyses. The partial correlations express the strengths of association between each TP dimension and the outcome measures, with personality held constant statistically. All these relationships remained significant with three exceptions: The associations between Past-Negative and work engagement, Future-Negative and CWB, as well as between DBTP and CWB. All these associations diminished below the significance threshold, and amounted to $r=-.07$, $p=.32, r=-.09, p=.19$, and $r=.10, p=.17$, respectively. Thus, relationships between TPs and job-related variables are not fully reducible to effects of personality traits.

\section{Discussion}

The present study analyzed the role of individual differences in time perspectives in shaping works attitudes (engagement and satisfaction) and behaviors (OCB and CWB). The analyses demonstrated meaningful relationships between these organizational criteria and three TP dimensions: Present-Fatalistic, Future-Negative, and Future-Positive. In line with our predictions, the effects of the former two proved undesirable, whereas the latter turned out to be a strong positive predictor of increased
Fig. 1 Path model illustrating associations between TPs, work attitudes and behaviours. $\mathrm{OCB}=$ Organizational Citizenship Behaviour, CWB = Counterproductive Work Behaviour

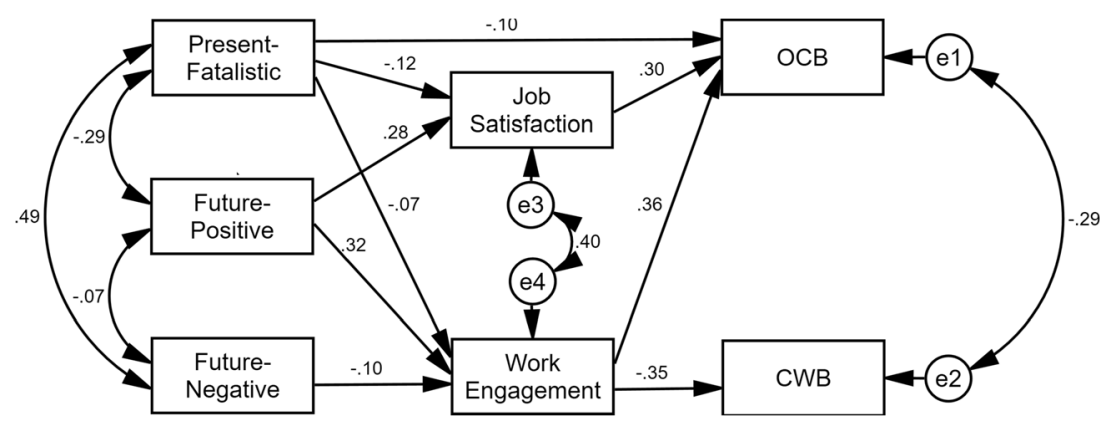


Fig. 2 Path model illustrating associations between BTP, work attitudes and behaviours. $\mathrm{OCB}=$ Organizational Citizenship Behaviour, $\mathrm{CWB}=$

Counterproductive Work

Behaviour, DBTP $=$ Deviation

from Balanced Time Perspective

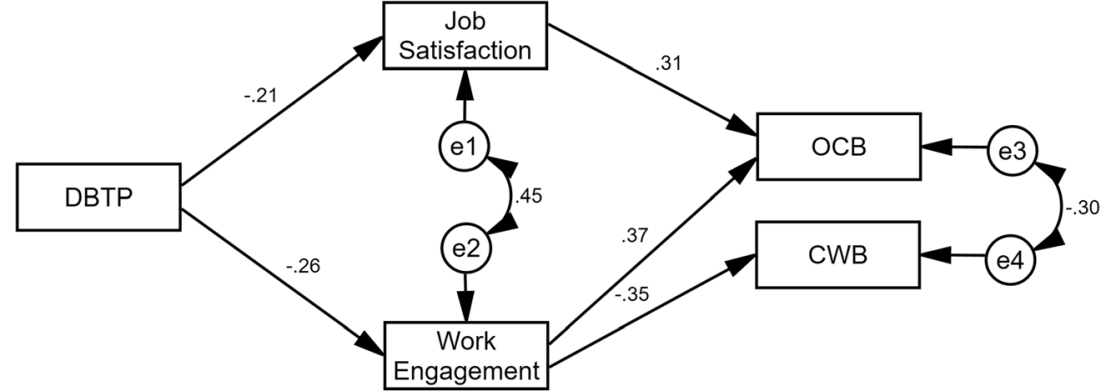

job engagement and satisfaction, elevated OCB and diminished CWB. The Future-Positive TP overlaps with the unitary Future dimension originally proposed by Zimbardo and Boyd (1999). The authors have emphasized various strengths of Future orientation that would be advantageous in the work setting. They describe Future-oriented individuals as ambitious, organized, time-pressured, and willing to sacrifice present enjoyment to meet career objectives. The current results support the idea that Future-orientation is adaptive for work, but they also show the importance of discriminating Future-Positive and FutureNegative TPs.

Moreover, the present study provided further evidence for the highly adaptive nature of BTP, which was associated with all the organizational criteria as hypothesized. The result is consistent with numerous recent studies emphasizing the key role of BTP in pursuit of happiness and social effectiveness (e.g., Boniwell et al. 2010; Stolarski et al. 2016a, b; Zhang et al. 2013). Individuals with a strong BTP seem to optimize their job attitudes and pro-organizational behaviors by making effective use of positive framing of temporal horizons, combined with an ability to effectively control negative, maladaptive perspectives.

The path models we tested provide further evidence for the legitimacy of Spector and Fox's (2002) claims regarding the profound role of affective states and attitudes towards the organization in shaping employees' organizational behaviors. They are also perfectly in line with conceptualizations and studies assuming that TPs may serve as a regulatory mechanism for affective functioning (Matthews and Stolarski 2015; Stolarski et al. 2014; Stolarski and Matthews 2016).

Although we did not measure burnout symptoms, the present results provide indirect evidence that TPs may be associated with this undesirable syndrome, because work engagement may be treated as a positive counterpart to the burnout phenomenon (Maslach et al. 2001). It would be interesting to broaden the present results taking into account also the negative aspects of job functioning. A recent study found ZTPI correlates of burnout that complement the current findings; i.e., Present-Fatalistic TP was positively associated with emotional exhaustion symptoms, and Future TP was negatively associated with perceptions of lack of accomplishment (Papastamatelou and Unger 2018).

Findings also confirmed the role of Big Five personality traits in predicting organizational outcomes, especially Extraversion and Openness. However, the majority of the associations between TPs and organizational attitudes and behaviors remained significant after controlling for the Big Five personality traits. This finding provides further evidence for incremental validity of TP dimensions over and above wellestablished individual difference factors (e.g., Daugherty and Brase 2010; Stolarski and Matthews 2016). However, further work may be necessary to fully differentiate relationships between the Big Five, TP, and adaptive job behaviors.

\section{Limitations and Future Research}

The present study has all the limitations typical for self-report, cross-sectional studies. The causal assumption that TPs influence job attitudes could be in fact reversed. The experience of helplessness and lack of influence on one's own job situation might foster a Present-Fatalistic perspective. Therefore, longitudinal designs would be desirable, e.g., investigating TP of recently recruited employees and tracking their attitudes and behaviors across the course of employment. Also, testing for associations between TPs and indicators of job behaviors and performance other than self-reports, e.g., 360-degree (Borman 1998) or supervisors' evaluations, would provide a valuable extension to the present findings.

Future studies could also analyze whether the effects of particular TPs vary between different professions and positions. It seems probable that some specific jobs may require different TP profiles for optimizing work quality. For instance, in jobs with a pronounced social component (such as, for instance, bellwether or seller), elevated levels of PresentHedonistic TP may prove valuable, whereas in positions requiring particularly high amounts of self-control (e.g., in financial brokers), the impulsivity component of PresentHedonism may turn out to be strongly maladaptive.

Although we controlled for personality traits, for reasons of feasibility we utilized only a brief scale for the Big Five, which 
displays poorer validity in comparison with full scales such as NEO-PI-R or IPIP. Future replications should control for personality using more reliable indicators in order to confirm the present results regarding TP's incremental validity in predicting work-related outcomes. Moreover, taking into account the nature of Present-Fatalistic TP, future research should control for work locus of control (Spector 1988), which has no counterpart in the Big Five model, but remains important for work-related outcomes.

TP theory provides a powerful theoretical framework for guiding practical interventions. TP can be effectively changed (Oyanadel et al. 2014), an approach that has been successfully used in both therapeutic (e.g., Sword et al. 2014) and coaching practice (Boniwell and Osin 2015). Developing developmental interventions aiming to balance the employee's TP profile, with particular emphasis on enhancing Future-Positive focus and reducing Present-Fatalistic perspectives, may turn out to be a fruitful strategy to improve employees' effectiveness, satisfaction and foster citizenship behaviors. There is also scope for mitigating impacts of maladaptive aspects of TP, such as Present-Fatalistic. Hardré and Reeve (2009) identify the problem of amotivation at work, in which employees go through the motions of work but do not value work activities. Present-Fatalistic individuals show comparable deficits in motivation and lack of interest in daily activities (Zimbardo and Boyd 1999) and are probably prone to amotivation, contributing eventually to burnout (Papastamatelou and Unger 2018). However, Hardré and Reeve (2009) also showed that managers could be trained to support autonomous motivation and greater workplace engagement, with benefits for employee motivation. Such programs might be especially valuable for supporting Present-Fatalistic employees.

Funding Information The present research was supported by National Science Center, Poland, grant no. 2014/13/D/HS6/02951.

\section{Compliance with Ethical Standards}

All procedures applied in the present studies were accepted by the Ethics Committee of the Department of Psychology at the University of Warsaw, and were in accordance with the 1964 Helsinki declaration and its later amendments or comparable ethical standards. Informed consent was obtained from all individual participants included in the study. This article does not contain any studies with animals performed by any of the authors.

Conflict of Interest Author Katarzyna Wojtkowska declares that she has no conflict of interest. Author Maciej Stolarski declares that he has no conflict of interest. Author Gerald Matthews declares that he has no conflict of interest.

Open Access This article is distributed under the terms of the Creative Commons Attribution 4.0 International License (http:// creativecommons.org/licenses/by/4.0/), which permits unrestricted use, distribution, and reproduction in any medium, provided you give appropriate credit to the original author(s) and the source, provide a link to the Creative Commons license, and indicate if changes were made.

\section{References}

Babcock-Roberson, M. E., \& Strickland, O. J. (2010). The relationship between charismatic leadership, work engagement, and organizational citizenship behaviors. The Journal of Psychology, 144(3), 313-326.

Bakker, A. B. (2011). An evidence-based model of work engagement. Current Directions in Psychological Science, 20(4), 265-269.

Bakker, A. B., Schaufeli, W. B., Leiter, M. P., \& Taris, T. W. (2008). Work engagement: An emerging concept in occupational health psychology. Work \& Stress, 22(3), 187-200.

Bajec, B. (2018). Relationship between time perspective and job satisfaction. International Journal of Human Resources Development and Management, 18(1-2), 145-165.

Berry, C. M., Ones, D. S., \& Sackett, P. R. (2007). Interpersonal deviance, organizational deviance, and their common correlates: A review and meta-analysis. Journal of Applied Psychology, 92(2), 410-424.

Boniwell, I., \& Osin, E. (2015). Time perspective coaching. In M. Stolarski, N. Fieulaine, \& W. van Beek (Eds.), Time perspective theory: Review, research, and application (pp. 451-469). Cham, Switzerland: Springer International Publishing.

Boniwell, I., Osin, E., Linley, P. A., \& Ivanchenko, G. V. (2010). A question of balance: Time perspective and well-being in British and Russian samples. The Journal of Positive Psychology, 5(1), 24-40.

Borman, W. C. (1998). 360 degree ratings: An analysis of assumptions and a research agenda for evaluating their validity. Human Resource Management Review, 7, 299-315.

Bruk-Lee, V., Khoury, H. A., Nixon, A. E., Goh, A., \& Spector, P. E. (2009). Replicating and extending past personality/job satisfaction meta-analyses. Human Performance, 22(2), 156-189.

Burch, G. S. J., \& Anderson, N. (2009). Personality at work. In P. J. Corr \& G. Matthews (Eds.), The Cambridge handbook of personality psychology (pp. 748-763). New York, NY, US: Cambridge University Press.

Carelli, M. G., Wiberg, B., \& Wiberg, M. (2011). Development and construct validation of the Swedish Zimbardo time perspective inventory. European Journal of Psychological Assessment, 27(4), 220-227.

Carstensen, L. L. (2006). The influence of a sense of time on human development. Science, 312(5782), 1913-1915.

Chiaburu, D. S., Oh, I. S., Berry, C. M., Li, N., \& Gardner, R. G. (2011). The five-factor model of personality traits and organizational citizenship behaviors: A meta-analysis. Journal of Applied Psychology, 96(6), 1140-1166.

Christian, M. S., Garza, A. S., \& Slaughter, J. E. (2011). Work engagement: A quantitative review and test of its relations with task and contextual performance. Personnel Psychology, 64(1), 89-136.

Clark, M. S., \& Isen, A. M. (1982). Toward understanding the relationship between feeling states and social behavior. In A. H. Hastorf \& A. M. Isen (Eds.), Cognitive social psychology (pp. 73-108). New York: Elsevier North Holland.

Costa, P. T., \& McCrae, R. R. (2009). The five-factor model and the NEO inventories. In J. N. Butcher (Ed.), Oxford handbook of personality assessment (pp. 299-322). New York, NY: Oxford University Press.

Czarnota-Bojarska, J. (2011). Zachowania obywatelskie w organizacji próba konstrukcji narzędzia pomiaru [citizenship behaviors in the organization: Construction of a measurement tool]. In J. CzarnotaBojarska \& I. Zinserling (Eds.), W kregu psychologii spotecznej [In the field of social psychology] (pp. 145-157). Warsaw: Wydawnictwa Uniwersytetu Warszawskiego.

Cunningham, K. F., Zhang, J. W., \& Howell, R. T. (2015). Time perspectives and subjective well-being: A dual-pathway framework. In M. Stolarski, N. Fieulaine, \& W. van Beek (Eds.), Time perspective 
theory; review, research and application (pp. 403-415). Cham, Switzerland: Springer International Publishing.

Czarnota-Bojarska, J. (2015). Counterproductive work behavior and job satisfaction: A surprisingly rocky relationship. Journal of Management \& Organization, 21, 460-470.

Dalal, R. S. (2005). A meta-analysis of the relationship between organizational citizenship behavior and counterproductive work behavior. Journal of Applied Psychology, 90, 1241-1255.

Daugherty, J. R., \& Brase, G. L. (2010). Taking time to be healthy: Predicting health behaviors with delay discounting and time perspective. Personality and Individual Differences, 48(2), 202-207.

Den Hartog, D. N., \& Belschak, F. D. (2012). Work engagement and Machiavellianism in the ethical leadership process. Journal of Business Ethics, 107(1), 35-47.

Díaz-Morales, J. F., Ferrari, J. R., \& Cohen, J. R. (2008). Indecision and avoidant procrastination: The role of morningness - Eveningness and time perspective in chronic delay lifestyles. The Journal of General Psychology, 135(3), 228-240.

Ferrari, J. R., \& Díaz-Morales, J. F. (2007). Procrastination: Different time orientations reflect different motives. Journal of Research in Personality, 41(3), 707-714.

Fila, M. J., Paik, L. S., Griffeth, R. W., \& Allen, D. (2014). Disaggregating job satisfaction: Effects of perceived demands, control, and support. Journal of Business and Psychology, 29(4), 639649.

Fox, S., Spector, P. E., \& Miles, D. (2001). Counterproductive work behavior $(\mathrm{CWB})$ in response to job stressors and organizational justice: Some mediator and moderator tests for autonomy and emotions. Journal of Vocational Behavior, 59(3), 291-309.

Gosling, S. D., Rentfrow, P. J., \& Swann, W. B. (2003). A very brief measure of the big-five personality domains. Journal of Research in Personality, 37(6), 504-528.

Hackman, J. R., \& Oldham, G. R. (1976). Motivation through the design of work: Test of a theory. Organizational Behavior and Human Performance, 16(2), 250-279.

Halbesleben, J. R. B. (2010). A meta-analysis of work engagement: Relationships with burnout, demands, resources and consequences. In A. B. Bakker \& M. P. Leiter (Eds.), Work engagement: Recent developments in theory and research (pp. 102-117). New York: Psychology Press.

Hardré, P. L., \& Reeve, J. (2009). Training corporate managers to adopt a more autonomy-supportive motivating style toward employees: An intervention study. International Journal of Training and Development, 13(3), 165-184.

Harter, J. K., Schmidt, F. L., \& Hayes, T. L. (2002). Business-unit-level relationship between employee satisfaction, employee engagement, and business outcomes: A meta-analysis. Journal of Applied Psychology, 87, 268-279.

Henry, H., Zacher, H., \& Desmette, D. (2017). Future time perspective in the work context: A systematic review of quantitative studies. Frontiers in Psychology, 8, 413.

Hoffman, B. J., Blair, C. A., Meriac, J. P., \& Woehr, D. J. (2007). Expanding the criterion domain? A quantitative review of the OCB literature. Journal of Applied Psychology, 92(2), 555-566.

Hough, L. M., Oswald, F. L., \& Ock, J. (2015). Beyond the big five: New directions for personality research and practice in organizations. Annual Review of Organizational Psychology and Organizational Behavior, 2, 183-209.

Jochemczyk, Ł., Pietrzak, J., Buczkowski, R., Stolarski, M., \& Markiewicz, Ł. (2017). You only live once: Present-hedonistic time perspective predicts risk propensity. Personality and Individual Differences, 115, 148-153.

Judge, T. A., Scott, B. A., \& Ilies, R. (2006). Hostility, job attitudes, and workplace deviance: Test of a multi-level model. Journal of Applied Psychology, 91, 126-138.
Judge, T. A., Hulin, C. L., \& Dalal, R. S. (2012). Job satisfaction and job affect. In S. W. J. Kozlowski (Ed.), The Oxford handbook of industrial and organizational psychology (pp. 496-525). New York, NY: Oxford University Press.

Judge, T. A., Thoresen, C. J., Bono, J. E., \& Patton, G. K. (2001). The job satisfaction-job performance relationship: A qualitative and quantitative review. Psychological Bulletin, 127(3), 376-407.

Kairys, A., \& Liniauskaite, A. (2015). Time perspective and personality. In M. Stolarski, N. Fieulaine, \& W. van Beek (Eds.), Time perspective theory; review, research and application (pp. 99-113). Cham, Switzerland: Springer International Publishing.

Łaguna, M., Bąk, W., Purc, E., Mielniczuk, E., \& Oleś, P. K. (2014). Krótki inwentarz osobowości TIPI-P w badaniach polskich [short personality inventory TIPI-P in polish studies]. Roczniki Psychologiczne / Annals of Psychology, 17(2), 403-419.

Laureiro-Martinez, D., Trujillo, C. A., \& Unda, J. (2017). Time perspective and age: A review of age associated differences. Frontiers in Psychology, 8, 101.

Lens, W., Paixao, M. P., Herrera, D., \& Grobler, A. (2012). Future time perspective as a motivational variable: Content and extension of future goals affect the quantity and quality of motivation. Japanese Psychological Research, 54(3), 321-333.

LePine, J. A., Erez, A., \& Johnson, D. E. (2002). The nature and dimensionality of organizational citizenship behavior: A critical review and meta-analysis. Journal of Applied Psychology, 87(1), 52-65.

Locke, E. A. (1976). The nature and causes of job satisfaction. In M. D. Dunnette (Ed.), Handbook of industrial and organizational psychology (pp. 1297-1349). Chicago: Rand McNally.

Marcus, B., Taylor, O. A., Hastings, S. E., Sturm, A., \& Weigelt, O. (2016). The structure of counterproductive work behavior: A review, a structural meta-analysis, and a primary study. Journal of Management, 42(1), 203-233.

Maslach, C., Schaufeli, W. B., \& Leiter, M. P. (2001). Job burnout. Annual Review of Psychology, 52(1), 397-422.

Matthews, G., \& Stolarski, M. (2015). Emotional processes in development and dynamics of individual time perspective. In M. Stolarski, N. Fieulaine, \& W. van Beek (Eds.), Time perspective theory; review, research and application (pp. 269-286). Cham, Switzerland: Springer International Publishing.

Mount, M., Ilies, R., \& Johnson, E. (2006). Relationship of personality traits and counterproductive work behaviors: The mediating effects of job satisfaction. Personnel Psychology, 59(3), 591-622.

Murphy, K. R. (1993). Honesty in the workplace. Pacific Grove, CA: Brooks/Cole Publishing.

Organ, D. W. (1988). Organizational citizenship behavior: The good soldier syndrome. Lexington, MA: Lexington Books.

Organ, D. W. (1997). Organizational citizenship behavior: It's construct clean-up time. Human Performance, 10(2), 85-97.

Organ, D. W., \& Kanovsky, M. (1989). Cognitive versus affective determinants of organizational citizenship behavior. Journal of Applied Psychology, 74(1), 157-164.

Organ, D. W., \& Ryan, K. (1995). A meta-analytic review of attitudinal and dispositional predictors of organizational citizenship behavior. Personnel Psychology, 48, 775-802.

Oyanadel, C., Buela-Casal, G., Araya, T., Olivares, C., \& Vega, H. (2014). Time perception: Results of a brief group intervention to change time perspective profiles. Suma Psicológica, 21(1), 1-7.

Papastamatelou, J., \& Unger, A. (2018). Differences in burnout proneness depend on time perspective-evidence from an occupational sample of industrial employees and MBA-students. Dialogues in Clinical Neuroscience \& Mental Health, 1, 52-57.

Podsakoff, N. P., Whiting, S. W., Podsakoff, P. M., \& Blume, B. D. (2009). Individual- and organizational-level consequences of organizational citizenship behaviors. Journal of Applied Psychology, 94(1), 122-141. 
Podsakoff, P. M., MacKenzie, S. B., Pain, J. B., \& Bachrach, D. G. (2000). Organizational citizenship behavior: A critical review of the theoretical and empirical literature and suggestions for future research. Journal of Management, 26(3), 513-563.

Robbins, S. P., \& Judge, T. A. (1993). Organization behaviour. London: Prentice Hall.

Robinson, S. L., \& Bennett, R. J. (1995). A typology of deviant workplace behaviors: A multidimensional scaling study. Academy of Management Journal, 38(2), 555-572.

Rudolph, C. W., Kooij, D. T. A. M., Rauvola, R. S., \& Zacher, H. (2018). Occupational future time perspective: A meta-analysis of antecedents and outcomes. Journal of Organizational Behavior, 39(2), 229248.

Rutt, J. L., \& Löckenhoff, C. E. (2016). Age patterns in mental representations of time: Underlying constructs and relevant covariates. Experimental Aging Research, 42(3), 289-306.

Schaufeli, W. B. (2016). Heavy work investment, personality and organizational climate. Journal of Managerial Psychology, 31(6), 10571073.

Schaufeli, W. B., \& Bakker, A. B. (2004). Job demands, job resources, and their relationship with burnout and engagement: A multi-sample study. Journal of Organizational Behavior, 25, 293-315.

Schaufeli, W. B., Salanova, M., González-Romá, V., \& Bakker, A. B. (2002). The measurement of engagement and burnout: A two sample confirmatory analytic approach. Journal of Happiness Studies, 3, 71-92.

Seijts, G. H. (1998). The importance of future time perspective in theories of work motivation. The Journal of Psychology, 132(2), 154-168.

Sircova, A., \& Mitina, O. V. (2008). Возрастная динамика временных ориентаций личности [Developmental dynamics of time orientations]. Voprosi Psikhologii, 2, 41-54.

Smith, C. A., Organ, D. W., \& Near, J. P. (1983). Organizational citizenship behavior. Journal of Applied Psychology, 68(4), 653-663.

Spector, P. E, (1988) Development of the Work Locus of Control Scale. Journal of Occupational Psychology, 61(4), 335-340

Spector, P. E. (1997). Job satisfaction. Thousand Oaks, CA: Sage.

Spector, P. E., \& Fox, S. (2002). An emotion-centered model of voluntary work behavior. Some parallels between counterproductive work behavior and organizational citizenship behavior. Human Resource Management Review, 12, 269-292.

Spector, P. E., \& Fox, S. (2005). A model of counterproductive work behavior. In S. Fox \& P. E. Spector (Eds.), Counterproductive workplace behavior: Investigations of actors and targets (pp. 151-174). Washington, DC: APA.

Spector, P. E., Fox, S., Penney, L. M., Bruursema, K., Goh, A., \& Kessler, S. (2006). The dimensionality of counterproductivity: Are all counterproductive behaviors created equal? Journal of Vocational Behavior, 68(3), 446-460

Stolarski, M., Bitner, J., \& Zimbardo, P. G. (2011). Time perspective, emotional intelligence and discounting of delayed awards. Time \& Society, 20(3), 346-363.

Stolarski, M., \& Cyniak-Cieciura, M. (2016). Balanced and less traumatized: Balanced time perspective mediates the relationship between temperament and severity of PTSD syndrome in motor vehicle accident survivor sample. Personality and Individual Differences, 101, 456-461.

Stolarski, M., Fieulaine, N., \& van Beek, W. (eds.)(2015). Time Perspective Theory; Review, Research and Application. Cham, Switzerland: Springer International Publishing.

Stolarski, M., Fieulaine, N., \& Zimbardo, P. G. (2018). Putting time in a wider perspective: The past, the present, and the future of time perspective theory. In V. Zeigler-Hill \& T. Shackelford (Eds.), The
SAGE handbook of personality and individual differences (pp. 592628). SAGE: Thousand Oakes, CA.

Stolarski, M., \& Matthews, G. (2016). Time perspectives predict mood states and satisfaction with life over and above personality. Current Psychology, 35(4), 516-526.

Stolarski, M., Matthews, G., Postek, S., Zimbardo, P. G., \& Bitner, J. (2014). How we feel is a matter of time: Relationships between time perspectives and mood. Journal of Happiness Studies, 15(4), 809827.

Stolarski, M., Wojtkowska, K., \& Kwiecińska, M. (2016a). Time for love: Partners' time perspectives predict relationship satisfaction in romantic heterosexual couples. Time \& Society, 25(3), 552-574.

Stolarski, M., Zajenkowski, M., \& Zajenkowska, A. (2016b). Aggressive? From time to time... uncovering the complex associations between time perspectives and aggression. Current Psychology, 35(4), 506-515.

Styła, R., Stolarski, M., \& Szymanowska, A. (2019). Linking childhood adversities with schizophrenia: A mediating role of the balanced time perspective. Schizophrenia Research. https://doi.org/10.1016/ j.schres.2019.05.021.

Sword, R. M., Sword, R. K., Brunskill, S. R., \& Zimbardo, P. G. (2014). Time perspective therapy: A new time-based metaphor therapy for PTSD. Journal of Loss and Trauma, 19(3), 197-201.

Szabowska-Walaszczyk, A., Zawadzka, A., \& Wojtaś, M. (2011). Zaangażowanie w pracę i jego korelaty: Adaptacja skali UWES autorstwa Schaufeliego i Bakkera [work engagement and its correlates: Adaptation of Schaufeli and Bakker's UWES scale]. Psychologia Jakości Życia [Psychology of Quality of Life], 10(1), 57-74.

Taber, B. J. (2013). Time perspective and career decision-making difficulties in adults. Journal of Career Assessment, 21(2), 200-209.

Taris, T. W., \& Schaufeli, W. B. (2015). Individual well-being and performance at work: A conceptual and theoretical overview. In M. van Veldhoven \& R. Peccei (Eds.), Well-being and performance at pork: The role of context (pp. 24-43). London: Psychology Press.

Unger, A., Yan, J., \& Busch, R. (2019). The relationship between the Zimbardo time perspective inventory and violations of business ethics in China: Unbalanced time perspective increases the acceptance of unethical business behavior. Time \& Society, 28(1), 83-106.

Wei, Y. C. (2012). Person-organization fit and organizational citizenship behavior: Time perspective. Journal of Management \& Organization, 18(6), 833-844.

Xanthopoulou, D., Bakker, A. B., Demerouti, E., \& Schaufeli, W. B. (2009). Reciprocal relationships between job resources, personal resources, and work engagement. Journal of Vocational Behavior, 74(3), 235-244.

Zajenkowski, M., Stolarski, M., Maciantowicz, O., Malesza, M., \& Witowska, J. (2016). Time to be smart: Uncovering a complex interplay between intelligence and time perspectives. Intelligence, 58 , $1-9$.

Zhang, J. W., Howell, R. T., \& Stolarski, M. (2013). Comparing three methods to measure a balanced time perspective: The relationship between a balanced time perspective and subjective well-being. Journal of Happiness Studies, 14(1), 169-184.

Zimbardo, P. G., \& Boyd, J. N. (1999). Putting time in perspective: A valid, reliable individual-differences metric. Journal of Personality and Social Psychology, 77, 1271-1288.

Zimbardo, P. G., \& Boyd, J. N. (2008). The time paradox. New York: Free Press.

Publisher's Note Springer Nature remains neutral with regard to jurisdictional claims in published maps and institutional affiliations. 